\author{
ATEC-2021 \\ Философские и культурологические аспекты современного образования, \\ проблемы сохранения и интерпретации историко-культурного наследия №5. \\ Философия межкультурного взаимодействия в онлайн.
}

\title{
Специфика восприятия поколением Z историко-культурного наследия в условиях сетевого бытия.
}

\author{
Mikhail G. Bresler Ufa State Petroleum Technological University ORCID 0000-0001-6985-8919
}

\begin{abstract}
Аннотация.
Вопросы межкультурного взаимодействия рассматриваются в статье в аспекте поколенческого восприятия различных стилей музыкальной и изобразительной культуры. Вопреки устоявшемуся мнению поколение $\mathrm{Z}$ воспринимает различные жанры искусства не через призму детерминации молодежной субкультуры, но как культурный информационный массив в целом. Противодействие сторонниками различных музыкальных и изобразительных жанров и стилей изобразительного искусства не свойственна существенной части поколения $\mathrm{Z}$, что связано с особенностями поколения «живущими» в цифровой среде, спецификой формирования настоящего этапа становления информационного/цифрового общества. В исследовании принимали участие студенты (18-24) технического и гуманитарного направления подготовки. Опрос, проведенный авторами, показывает, что среди молодого поколения распространены ценности метамодерна. Около половины опрошенных идентифицирует себя как гражданина страны, около трети как представителя этноса и/или религии. В области культурных предпочтений большинство показывает позитивное отношение к самым различным стилям как в области классического, так и в области современного музыкального и изобразительного искусства. Примерно равные доли опрошенных выделяют в качестве любимого стиля классическое и различные стили современного искусства. В тоже время у поколения Z не наблюдается противодействие между сторонниками различных стилей, что было характерно для
\end{abstract}

Ключевые слова. Поколение Z, классическая музыка, джаз, современная музыка, толерантность, терпимость

Generation Z

Abstract.

Keywords. Generation Z, classical music, jazz, contemporary music, tolerance, tolerance

\section{Introduction}

Начало XXI века характеризуется новым этапом цивилизационного развития информационного/цифрового общества, сопровождающимся глобальной трансформацией самой структуры межличностных, межгрупповых коммуникаций, а также существенными изменениями в массовом сознании в первую очередь молодого поколения. «Цифровая сфера», проявляющаяся в смене инструментов и каналов коммуникаций в виде появившихся в этот период смартфонов и интернет-сервисов социальные сети, а также бурным развитием цифровых технологий стала основой этапа становления информационного /цифрового общества. Новое поколение, названное поколением Z «цифровые аборигены» (Prensky M., 2001) формируется уже в новом информационном/цифровом обществе иным, нежели предшествующие поколения (Howe, N, Nadler R. 2008). Рожденные «со смартфоном в руках» это поколение представлено уже вполне сформированными личностями 18-24 лет со своими ценностями, идеями идеалами (Шамис Е.М., 2020). Представители этого поколения уже сейчас являются студентами университетов, а через 3-5 лет станут активной частью общества, определяющие тенденции развития общества в целом.

При изучении нами молодого поколения, о чем было изложено в раннее опубликованных трудах (Bresler, Galiullina, \& Gerasimova, 2020) были выявлены существенные отличия в приоритете ценностей от предыдущих поколений, что обусловлено рядом причин:

Во-первых, это бурное развитие информационного/цифрового общества, переход на стадию становления, в котором происходит трансформация, охватывающая все общество в целом, включая институты общества, организации, экономические, политические, социальные процессы.

Во - вторых, поколение Z называют «цифровыми аборигенами», то есть изначальными жителями цифровой среды, в отличие от предшественников (X, Y), которые вынуждены осваивать цифровые технологии, будучи взрослыми.

В-третьих, само поколение в нашей стране, формируется в несколько иных условиях чем, предыдущие. Если поколение X (1960 - конец 1970-х г.р.) формировались в условиях холодной войны, а поколение Y (1980 до середины 1990-х) в условиях распада СССР и экономико- политических реформ, то поколение $\mathrm{Z}$ родилось 
уже в относительно стабильном обществе страны с передовыми информационно-коммуникационными технологиями, что позволяет считать Z первым глокальным поколением, чье развитие сходно с аналогичным развитием молодежи иных развитых стран.

Существенные отличия нового поколения выражаются в большей прагматичности, уходу от романтических ценностей и декларированную независимость от благорасположения властных структур. Что, как отмечают эксперты, изучающие поколение Y (Никонов, Шамис, 2017 ), (Yagafarova, Shamshutdinova, Akhmetova, \& Adigamova, 2019) было характерно для предыдущих поколений X и Y.

В работах, опубликованных в течение последних 5-10 лет было высказано много предположений по поводу формирующегося поколения $\mathrm{Z}$, что послужило поводом $\mathrm{K}$ созданию нескольких устойчивых предположений, «мифов», подробно рассмотренных в работе ученых НИУ ВШЭ Н. В. Богачевой и Е. В. Сивак (Богачева, Сивак, 2019) «разоблачение» или подтверждение которых требует дополнительных исследований. Генезис мифов связан, по нашему мнению, со сложностью изучения поколения в период формирования самого поколения совпавшего с глубинной трансформацией общества, в связи с переходом на новую стадию цивилизационного развития. Начатые нами в 2020 г. исследование изначально учитывало как специфику этапа становления информационного /цифрового общества, так достижением существенной части представителей поколения Z совершеннолетнего возраста и приобретения ими экзистенциального опыта. В результате были выявлены специфические черты поколения. В частности - сетевая солидарность поколения, как сообщества детей, родителей, иных родственников, друзей с которыми состоят в постоянном взаимодействии (Галиуллина С.Д. и др. 2020). Ценность семьи в ее расширенном понятии, формирует межличностные связи, позволяющие получать всем участникам сообщества необходимые преференции, влияющие на коммуникации вне данного сообщества. Это новое явление, в поколении Y социальные связи ограничиваются слабыми связями (Granovetter, 1973) и нуклеарной семьей, влияние которой уменьшается со временем. Напротив, у Z нуклеарная семья получает развитие в сообщество с сильными родственными, дружественными, профессиональными связями. Наблюдается активная позиция по укреплению семьи/сообщества. Пребывая внутри семьи/сообщества представитель поколения Z в первую очередь ищет близкие ценности, сознательно избегая спорных тем внутри сообщества. Понимая, что цифровая среда, в которой представитель поколения Z находится с детского возраста (10-11 лет), является сложной и чуждой для представителей старшего поколения, они высказывают готовность помогать старшему поколению войти в цифровой мир.

Это поколение можно назвать поколением метамодернизма, в терминологии Р. в. д. Аакера (Аккер 2020). Они не испытывают аффект цифровой среды, как представители предыдущих поколений, но подвержены осцилляции между ценностями прошлого и будущего, относительно времени Z - поколения. Нам представляется вполне закономерным отсыл к метамодернизму в рамках данного исследования, как и в целом к исследованиям поколения Z. Метамодернизм, как явление культуры есть результат стремительных изменений социальных процессов общества, которые привели к трансформации институтов и организаций. Раннее мы рассматривали метамодернизм вслед за авторами этой концепции, как «ответную реакцию общественного сознания в форме возврата к символам прошлого» (Бреслер, Рабогошвили, \& Сулейманов. 2020). Наши исследования и факты последнего времени свидетельствуют о более широком распространении этого явления. Ценности предыдущих стадий цивилизационного развития не исчезают, но адаптируются под влиянием нового времени. Мы предполагаем, что поколение $\mathrm{Z}$ воспринимает историко-культурное наследие и современную им культуру как недетерминированное культурное поле, симулякр общечеловеческой культуры. Основанной на ценностях как формирующейся информационной/цифровой стадии, так и предыдущих стадий цивилизационного развития.

\section{Materials and Methods}

В данном исследовании применен структурно - функциональный подход к исследованию ценностей и приоритетов поколения Z, в его дальнейшем развитии - информационно- коммуникационном методе. Общенаучный метод наблюдения был дополнен количественным и качественным исследованием ценностей и приоритетов активной, образованной частью поколения, а именно студентов уфимских университетов в возрасте 18-24 года. Количественный опрос был проведен с помощью анкеты Google Forms, ссылка на которую распространена среди студентов в возрасте 18-24 лет, гуманитарных и технических направлений подготовки, представляющих поколение Z. Всего было опрошено 710 респондентов по двум формам анкет. Первый опрос (310 респондентов) ставил своей целью изучение самоидентификации, отношению к этническим ценностям, второй (400 респондентов) отношение к различным стилям музыкального и изобразительного искусства, косвенным образом также свидетельствующие о самоидентификации респондентов. Одновременно была проведена серия фокус групп репрезентативных референтной группе анкетируемых.

\section{Results}

\section{1. Иерархия ценностей поколения $\mathrm{Z}$}

Сетевая форма коммуникаций предусматривает одновременное пребывание человека в различных сетевых сообществах, объединенных близкими ценностями участников. Поколение Z, пребывающая в цифровой среде, с преобладанием сетевой формы коммуникаций, разделяет широкий спектр ценностей, присущих различным стадиям цивилизационного развития. Это относится в первую очередь к самоидентификации человека. Как видно на рисунке № 1. на вопрос: «Как бы Вы идентифицировали себя?» участники исследования выбирали гражданскую -52,9\%, этническую - 27,4\%, конфессиональную - 5,4\% 
идентификацию, подразумевающих приоритет прежде всего ценностей архаичного, аграрного и индустриального стадий цивилизационного развития, тогда как ценности который можно отнести к информационному/цифровому обществу отмечают в качестве приоритетных лишь 14,3\% респондентов. При ответе на этот вопрос среди участников фокус-групп наблюдается примерно такое же соотношение долей ответов с указанием на этническую и конфессиональную идентичность - 25\% и 5\% соответственно. В тоже время в качестве «прежде всего гражданина» себя определило значительное, но несколько меньшее число участников - 40\%, а различные формы идентификации, отнесенные нами к сформированным на основе ценностей информационного/цифрового общества - 30\%. Как видим при общим сохранении тенденции определяется некоторая разность результатов, связанная по нашему мнению с желанием участников фокус групп выбрать для публичного озвучания более оригинальный ответ.

\section{0 ответов}

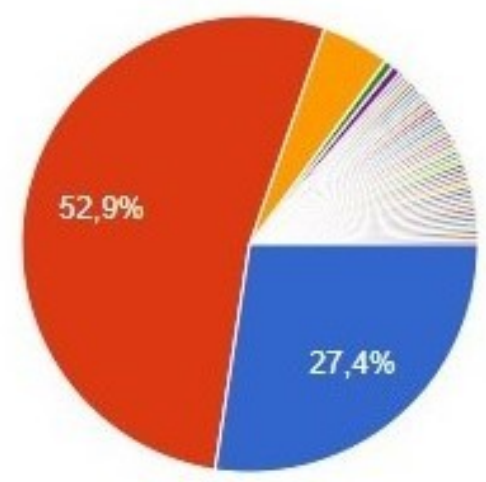

Рис.1. Самоидентификация участников опроса: «Как бы Вы идентифицировали себя?»

1. Прежде всего я - гражданин своего государства (52,9\%); 2. Прежде всего я представитель своего этноса (27,4\%); 3. Прежде всего я представитель своей религии (5,4\%); 4- 8 Прежде всего я личность, человек, представитель класса, человек мира, студент университета и др. (14,3\%). Источник - собственные исследования

Ответы на вопросы этой анкеты показали, что респонденты в большинстве своем, отмечают «язык моего этноса», как лично важную ценность. Так ответили 68,4\% респондентов. Определяющую роль «языка моего этноса» для познания культуры этноса отметили 75,5\% и в то же время большинство респондентов считает, что в «принципе, не обязательно понимать язык моего этноса, чтобы считаться ценителем культуры моего этноса, так как есть хорошие переводы, успешная экранизация, адаптация». Так ответили 62.3\% опрошенных и в тоже время 65,8\% опрошенных не считают, что язык своего этноса изучать не нужно, несмотря на то что «мы живем в условиях стремительных глобальных изменений», которые могут привести к исчезновению многих этнических языков. При этом сам процесс отмирания этнических языков 60,6\% опрошенных считают негативным явлением. По мнению 63,5\% респондентов процесс изучения языков этносов считают важным и нужным, а 68.7\% испытывают удовлетворения, радости, гордости, когда слышат речь на языке своего этноса.

Анализ высказываний участников фокус-групп подтверждает данные опроса. Неоднократно были высказаны мнения о необходимости изучения этнических языков для укрепления коммуникации со старшим поколением, укрепления семьи в целом. При этом представители поколения Z, в отличие от старшего поколения, не считают драматичной ситуацию с обучением языкам этносов Республики Башкортостан. Их вполне достаточно тех инструментов, которые существуют в настоящее время. При этом они предполагают, что в будущем они будут обучать своих детей языкам этносов Башкортостана, но только в том случае если дети сами этого захотят. В этом проявляется прагматизм поколения Z. C их точки зрения полилингвальность увеличивает возможность создания и расширения коммуникаций, что ведет к укреплению связей в сообществе.

Анализ выше приведенных данных доказывает существование существенной доли этнических ценностей, сформированных в аграрном обществе, в общей иерархии ценностей молодого поколения информационного/цифрового общества, с учетом того, что сами ценности прошли адаптацию к изменившимся условиям новой стадии цивилизационного развития.

\section{2. Поколение $\mathrm{Z}$ и стили музыкального и изобразительного} искусства.

На основе знаний, полученных при анализе первой сессии анкетирования, была проведена вторая, вопросы которой были сосредоточены на отношении к различным стилям музыкального и изобразительного искусства. Всего было заполнено 400 анкет, при этом часть респондентов не ответила все вопросы анкеты. Опрос был также проведен среди студентов университетов и колледжей, в том числе и обучающихся 
музыкальному и изобразительному искусству и смежным областям. Целью опроса стало выявление отношения поколения Z к различным стилям музыкального и изобразительного искусства. По роду деятельность распределение показано на рисунке №2. Как видно из диаграммы 85,6\% участников опроса считают свою деятельность далекой от искусства, но в то же время не равнодушны музыке и живописи, в то время как 14,4\% участников работают/учатся в сфере искусства. Отметим, что при анкетировании выборка опрашиваемых была специально ограничена нами студентами университета из регионального центра. Респонденты по большей части относятся к среднему классу, что позволило отграничить данную категорию респондентов от маргинальных групп, с уклоном в криминалитет молодежных субкультур. Опрос также не предусматривал выявление политических пристрастий респондентов и отношения к различным течениям радикального религиозного и этнического движений, за исключением вопросов приведенных выше.

\section{Род деятельности по отношению к искусству}

394 ответа

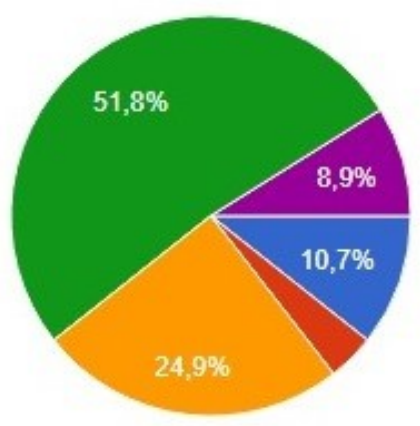

1 Я просессионал (музыкант, композитор, актер театра и кино, ху...

2 Я работаю в медиа -сфере (телевидение радио, библиотека, ре..

З Я люблю искусство, но моя работа с ней связана

4 Работа с искусством не связана, но я люблю бывать на концертах. и тд.

5 Работаю в сфере далеком от искусства, к искусству равнодушен

Рис. 2. Род деятельности участников опроса по отношению к искусству. Источник - собственные исследования

Интерес к искусству у большинства участников опроса объясняется тем, что с распространением цифровых технологий искусство становится доступным для самых широких слоев населения. Не только пассивное созерцание, но и широкое обсуждение в социальных сетях и оценка живописного и музыкального материала. Другим важным фактором проявления большинством интереса к искусству, творчеству в целом, есть наличие существенной доли творческого труда в современной производственной деятельности. Искусство рассматривается как одна из областей профессионального творческого труда, то есть часть повседневной для человека креативной сферы деятельности. Информационное/цифровое общество сняло покров сакральности с искусства. Доступность музыки и живописи в их цифровых проекциях, возможность сотворчества, возможность каждого человека, ограниченная лишь его желаниями и возможностями создавать произведения искусства и распространять на неограниченный круг лиц.

Известно, что у предыдущих поколений декларирования пристрастий в области музыки или живописи служило знаком идентификации. Пристрастие к различным музыкальном стилям и в меньшей степени различным стилям изобразительного искусства было маркером для определения принадлежности молодых людей к той или иной субкультуре, что зачастую приводило к конфликтам между представителями различных сообществ у поколения Х и Y (Беляева, 2010)

В тоже время у «живущих в цифровой среде» поколения Z отношение к музыкальному и изобразительному искусству иное. В полном противоречии с опытом автора, относящего себя к поколению Х, вопрос, описывающий реальное событие на молодежной вечеринке, вызвал парадоксальное распределение ответов. 


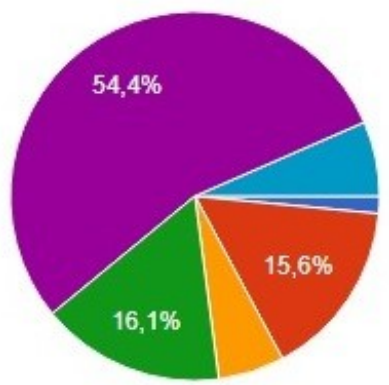

1 попрошу его выключить

2 попрошу его включить нечто более близкое обществу

3 попрошу других гостей проявить терпение

4 поддержу - начну подпевать подыгрывать танцевать

5 предложу всем гостям по очереди включать их любимую музыку

Вариант 6

Рис. 3. Ситуационная задача: на вечеринке один из гостей включил запись музыкального произведения не популярного у других гостей. Вы скорее всего... Источник - собственные исследования

Автор ожидал, что молодежная аудитория ответит негодованием на действия «гостя». Но, как показано на рисунке №3, наибольшее число ответов связано именно с нейтральной (предложу всем гостям по очереди включить их любимую музыку - 54, 4 \%) или позитивной (поддержу - начну подпевать, подыгрывать, танцевать 16,1\%) реакцией. Меньшинство, то есть около 20 \% высказывают скорее негативную реакцию (15,1 \% выбрали ответ «я попрошу его включить нечто более близкое обществу», а 5,8\% предполагают попросить других гостей «проявить терпение»). Экстраполируя распределение реакций участников, можно сказать, что большинство молодых людей воспринимает произведение музыкального, изобразительного искусства без проявления неприязни к какому-то стилю, что касается не только жанров современной популярной, но и классической музыки. Это подтверждает и выбор ответов на другие вопросы анкеты.

На вопрос об отношении к музыке входящий в плейлист участников наиболее популярным был ответ: «В моем плейлисте много музыки различных жанров» (77,8\%). Такая же доля участников ответила: «Хорошая музыка всегда актуальна» (77,8\%). При этом участники, рожденные после 2000 года, актуальной назвали музыку 1970-1980-х гг. (4, 5\%), а также 1990-х (7,1\%). Вопреки расхожему мнению поколение Z принимает классическую симфоническую музыку (см. рис. 4)

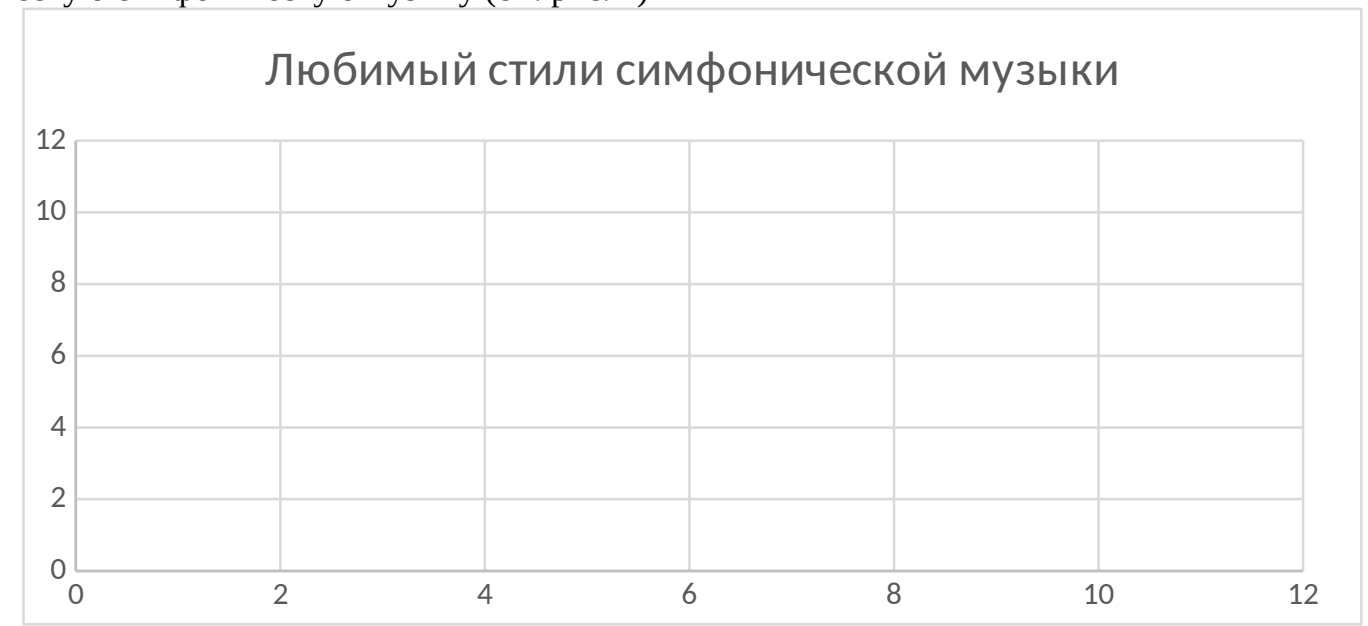

Рисунок 4. Любимый жанр симфонической музыки.

1.классическая современная музыка; 2. современная симфоническая музыка; 3. Различные стили авангарда симфонической музыки; 4. Этно-стиль симфонической музыки; 5. Этно (моего этноса) стиль симфонической музыки; 6. Нет любимого жанра - есть любимые авторы/исполнители; 7. Не понимаю симфоническую музыку - слушаю все; 8. Не понимаю и не люблю слушать.

Доля участников, назвавших любимым стилем классическую симфоническую музыку (участники могли выбрать несколько ответов) - 28,1\%, а 31,2\% затруднились выделить отдельный стиль и ответили, что они в области классической музыки у них есть любимые авторы/исполнители. Только 16,1 \% заявили, что не любят классическую музыку как таковую. 


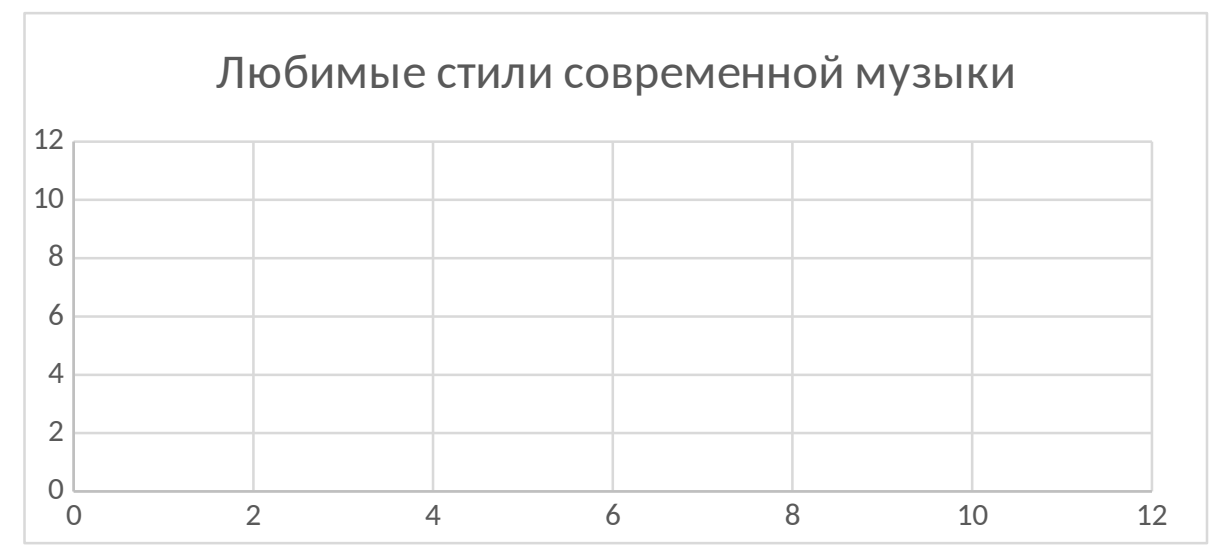

Рис. 5 Любимый стиль современной музыки. 1. Джаз; 2. Рок; 3. Хеви - металл; 4. Панк-рок; 5. Фолк-рок; 6. Рэп; 7. Поп - музыка; 8. Этническая музыка; 9. Этническая музыка моего этноса. Источник - собственные исследования

В области современной музыки (см. рис. 5) ожидаемо наибольшую долю заняла поп-музыка, как наиболее массовое направление (67,3\%), на втором месте рэп (45,6\%). Такая большая доля поклонников стиля рэп связана как с популярным исполнителем А. Моргенштерн - земляком уфимских студентов, так и с тем, что зарождение и развитие этого стиля наиболее близко к поколению Z. Однако другие направления современной музыки также вызывают интерес. Рокк -37\%, джаз -26, 6\%, этническая музыка - 16,7\%. В анализе ответов отдельных участников, выбравших несколько направлений не выявлено сколь бы то существенной корреляции с предпочтениями и ценностями. Участники одновременно отмечают рокк и рэп, джаз и этническую музыку и др.

Касательно изобразительного искусства больше половины участников (52,7\%) отметили, что им нравятся все стили, меньшинство признались в своем невежестве в этой области культуры (20\%), и около трети респондентов выделили отдельные направления изобразительного искусства.

Ограничения на посещения мероприятий, введенных в связи с пандемией Covid19, наложили отпечаток на ответы вопроса: «Мероприятие культуры, которое вы хотели бы посетить?» (см. рис. 6).

\section{Мероприятия которые вы хотели бы посетить}

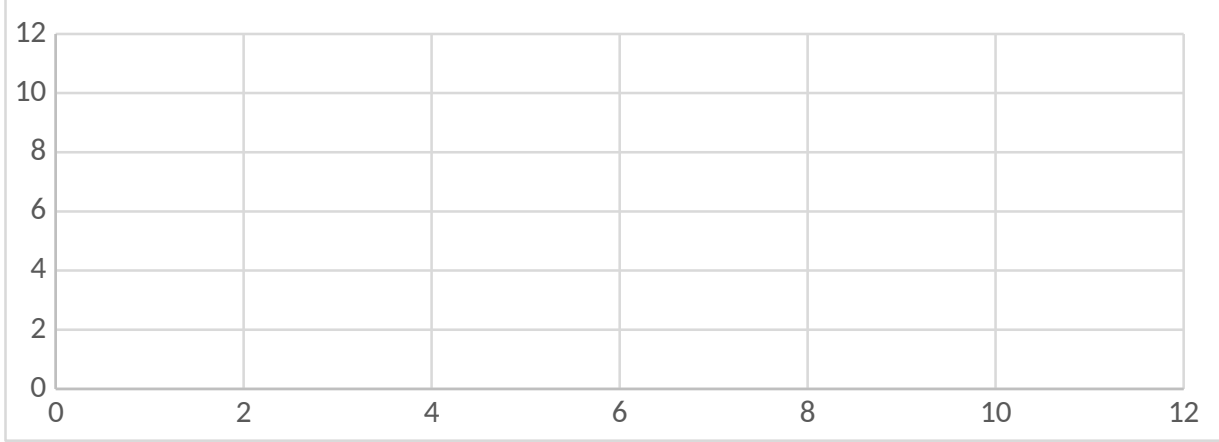

Рис. 6. После отмены режима ограничения на проведение массовых мероприятий какое мероприятия вы хотели бы посетить в первую очередь. 1. концерт симфонической музыки; 2. Классическую оперу или балет; 3. Вечер джазовой музыки; 4. Рокконцерт; 5. Концерт поп-музыки; 6. Музей классической живописи и скульптуры;7. Музей современного искусства. Источник - собственные исследования

Молодые люди вынуждены ограничить себя на длительный срок от посещения массовых мероприятий. Не случайно наибольшая доля ответов пришлась на мечту о посещения концерта поп-музыки (53, 9\%) и музея современного изобразительного искусства (50, 1\%), но на втором месте участники указывают мечту о посещении театра оперы и балета (43, 5\%), а также музея классического изобразительного искусства (43\%). Более нишевые концерты симфонической музыки, рокк или джаза хотели бы посетить около трети респондентов.

\section{Discussion \& Conclusion}

Проведенное исследование подтвердило в целом, отмечаемое российскими и зарубежными учеными поколения Z, множественность ценностей, включая ценности как присущие информационному/цифровому обществу, так и предыдущим стадиям цивилизационного развития. С точки зрения метамодернизма это свидетельство осцилляции сознания, но поколение $\mathrm{Z}$ живет уже в ином мире, мире сетевого бытия, где множество ценностей не встраиваются в общую иерархию, но существуют в сложном сетевом взаимодействии. Сетевое взаимодействие символов, идей, идеалов создают у представителей поколения Z сферу, где во взаимодействии сосуществуют символы прошлого и будущего в их проекции на настоящее. 
Молодые люди в большинстве своем не разделяют современную им культуру на «свою» и «чужую», выделяя лишь соответствующую и не соответствующую ценностям идеям, идеалам. Приверженность определенным стилям музыкальной культуры коррелируется с пребыванием молодого человека во множестве сообществ, различаемых по ценностям, которые являются общими для участников каждого из сообществ. Цифровая среда позволяет в краткие промежутки времени создавать подобные сообщества, также как делает доступным музыкальные произведения практически всего спектра стилей и направлений.

Терпимость к различным жанрам сопровождается десакрализацией символов принадлежности к различным музыкальным направлениям. Этот процесс не исключает, того, что отдельный композитор, исполнитель, скульптор становится лидером мнений. Сакральность творчества снижается в связи с тем, что творческий труд становится неотъемлемой частью производственной деятельности самых широких слоев населения, прежде всего, работающих в области цифровых технологий.

Исходя из этого, можно предположить, что у поколения Z не будет большой проблемы привлечения внимания к симфонической музыке, джазу или иному музыкальному стилю или стилю изобразительного искусства, и в целом к культурному наследию оно создано и распространяется в удобном для «сетевых аборигенов» формате цифровой информационной среды.

\section{Acknowledgments}

Автор статьи приносит благодарность заведующей кафедрой Международных отношений, истории и востоковедения профессору Галиуллиной С.Д., а также руководству Института и Университета за создание условий для написания этой статьи.

Благодарность моему коллеге, доценту Ахмадееву К.Н.(УГНТУ) за помощь в создании анкет и Хасаншину А.Д. (Уфимский институт искусств) за консультации в области искусствоведения

\section{Список литературы}

1. Беляева К. А. (2010) Молодежные субкультуры: социально-философский феномен. Вестник Таганрогского института имени А.П. Чехова, 2, 12-17

2. Бреслер М.Г. (2019) Метаморфозы творчества в сетевой коммуникации постмодерна. Медиа в современном мире. 58-Е Петербургские чтения. Сборник материалов Международного научного форума. Ответственный редактор В.В. Васильева. СанктПетербург: Издательство Санкт-Петербургского государственного университета, 1, 92-94.

3. Бреслер М.Г. (2020) Онтология сетевого бытия: монография. Уфа: Изд-во УГНТУ, 2020. -130 c.

4. Бреслер М.Г., Рабогошвили А.А., Сулейманов А.Р. (2020) К вопросу о роли символического в идентификации человека информационного общества. Studia Culturae. 3 (45) C. 18-34.

5. Галиуллина С.Д (ред.) (2020) Конструирование образа будущего. Голос поколения Z из сердца Евразии: прикладное исследование/ Constructing the Future. The Voice of Generation $Z$ from the Heart of Eurasia: An Applied Research.Коллективная монография Уфа: УГНТУ,.

6. Р. ван ден Аккер (2020) Метамодернизм. Историчность, Аффект и Глубина после постмодернизма Москва. РИПОЛ классик

7. Богачева, Н. В. Сивак Е. В. (2019) Мифы о «поколении Z» Москва: Национальный исследовательский университет «Высшая школа экономики».

8. Никонов Е., Шамис, Е. (2017) Необыкновенный ИКС (теория поколений). Москва: Издательский дом университета «Синергия».

9. Омельченко Е. Л. (ред.) (2019) Созидательные поля межэтнического взаимодействия и молодежные культурные сцены российских городов 2015-2019 Результаты исследования Санкт- Петербург: Научно-исследовательский университет - Высшая школа экономики. URL: https://spb.hse.ru/soc/youth/rnf/paper

10. Шамис Е. М.(2020) Ценности поколений в России на 2020 год. RUgeneration - Poсcийская школа теории поколений URL: https://rugenerations.su/2020/06/17/\%d1\%86\%d0\%b5\%d0\%bd\%d0\%bd\%d0\%be 
\%d1\%81\%d1\%82\%d0\%b8-\%d1\%80\%d0\%b0\%d0\%b7\%d0\%bd\%d1\%8b\%d1\%85-\%d0\%bf \%d0\%be\%d0\%ba\%d0\%be\%d0\%bb\%d0\%b5\%d0\%bd\%d0\%b8\%d0\%b9-\%d0\%b2-

\%d1\%80\%d0\%be\%d1\%81\%d1\%81\%d0\%b8\%d0\%b8-\%d0\%bd\%d0\%b0-20/

11. Howe, N, Nadler R. (2008) Millennials \& K-12 Schools. London: Life Course Associates, pp.109-111

12. Parker,K. Igelnik, R. (2020) On the Cusp of Adulthood and Facing an Uncertain Future: What We Know About Gen $\mathrm{Z}$ So Farh. Pew Social Trends URL: https: //www.pewsocialtrends.org/essay/on-the-cusp-of-adulthood-and-facing-an-uncertainfuture-what-we-know-about-gen-z-so-far/

13. Prensky M. (2001) Digital Natives, Digital Immigrants. On the Horizon - MCB University Press. Vol. 9 No. 5 URL: https://marcprensky.com/writing/Prensky\%20-\%20Digital \%20Natives,\%20Digital\%20Immigrants\%20-\%20Part1.pdf

14. Yagafarova D, Shamshutdinova N., Akhmetova E, \& Adigamova O. (2019) X and Y Generations in Bashkortostan Republic: Continuty and Transformation of Values The European Proceedings of Social \& Behavioural Sciences EpSBS. https://doi.org/10.15405/epsbs.2019.12.04.450

15. Bresler M.G., Galiullina S.D., Gerasimova D.I. (2020) Transformation of the values of Generation Z - residents of the digital society of sustainable development. E3S Web Conf. Volume 208, 2020. First Conference on Sustainable Development: Industrial Future of Territories (IFT 2020) DOI https://doi.org/10.1051/e3sconf/202020809043

16. Granovetter, M. S. (1973) «The strength of weak ties». American Journal of Psychology, 78 (6), pp. $1360-1380$. 